\title{
Butoconazole and miconazole in treating vaginal candidiasis
}

\author{
C S BRADBEER, * S R MAYHEW, † AND D BARLOW* \\ From the *Department of Genitourinary Medicine, St Thomas's Hospital, London, and the + Eaton \\ Socon Health Centre, Huntingdon
}

SUMMARY In a single blind trial, a three day course of butoconazole nitrate cream was compared with a seven day course of miconazole nitrate cream, both applied intravaginally, in treating vaginal candidiasis. They were equally effective.

The cure rate for patients treated with butoconazole was $82 \cdot 8 \%$ at the first follow up (a mean of $18 \cdot 4$ days from the beginning of the treatment) and $76 \cdot 7 \%$ at second follow up (a mean of $40 \cdot 4$ days). Cure rates for patients treated with miconazole were $84 \cdot 4 \%$ and $75 \cdot 8 \%$ respectively. The differences between these cure rates were not significant.

\section{Introduction}

Butoconazole is a new imidazole antifungal agent, which is highly active in vitro ${ }^{1}$ and in vivo ${ }^{2}$. Its use in treating vaginal candidiasis in laboratory animals has suggested that it is more active than miconazole or clotrimazole, and that butoconazole might therefore be used in lower doses than those required for the other two drugs, ${ }^{3}$ with improvement in patient compliance. $^{45}$

\section{Patients, materials, and methods}

\section{MATERIALS}

Both drugs were made up as intravaginal creams containing $2 \%$ of the active agent. The dose of butoconazole prescribed was $5 \mathrm{~g}$ nightly for three nights. The dose of miconazole was $10 \mathrm{~g}$ nightly for seven nights. The drugs were packed in identical boxes and coded, using a random number table, by Syntex Pharmaceuticals (Maidenhead, Berkshire, England). The investigators were unaware of which product was being prescribed.

\section{SELECTION OF PATIENTS}

Patients from the department of genitourinary medicine at St Thomas's Hospital and the Eaton Socon Health Centre, Huntingdon, were enrolled in the trial if they had symptoms of vulvovaginal candidiasis and a positive culture for yeasts with or

Address for reprints: $\mathrm{Dr}$ C S Bradbeer, Department of Genitourinary Medicine, St Thomas's Hospital, London SE1 7EH

Accepted for publication 29 November 1984 without initial diagnosis by direct microscopy. They were required to give informed zonsent and to be over 18 years of age.

Patients were excluded from entry if they: (1) had any other sexually transmitted disease or gynaecological abnormality requiring treatment; (2) had a disease known to predispose to candidiasis such as diabetes mellitus, or were receiving antibiotics or corticosteriods; (3) were pregnant; (4) had used antifungal medication in the week before entry; or (5) were expected to menstruate within seven days of the start of treatment.

Their sexual partners were not seen or treated and no restrictions were placed on sexual intercourse.

Approval for this trial was obtained from the Ethical Committee at St Thomas's Hospital.

\section{INVESTIGATIONS}

At the first visit each patient was asked the duration of her symptoms. Discharge, itching, and burning were each graded on a four point scale (none $=0$, mild $=1$, moderate $=2$, and severe $=3$ ). These scores were added to give an arbitrary index of severity.

A vaginal examination was performed to exclude other pelvic disease or abnormality, samples of vaginal discharge were Gram stained for immediate microscopical examination, and plates were set up for yeast culture.

Each patient was instructed in the application of vaginal cream and given a 14 day diary card to record daily symptom changes and any side effects under the headings of (a) leakage of the preparation, (b) staining, (c) odour, and (d) others. 
Patients were asked to return at 14 and 35 days to be seen by CSB at St Thomas's Hospital and SRM at Eaton Socon Health Centre. At these visits further Gram stained smears and cultures were obtained.

\section{PATIENTS}

We studied 69 patients, 39 from the Eaton Socon Health Centre and 30 from St Thomas's Hospital. One patient was withdrawn after yielding a negative culture, having already received butoconazole with no side effects, and is excluded from all analyses. Of the remaining 68 patients, 35 received miconazole nitrate cream and 33 butoconazole nitrate cream.

The two groups of patients were well matched (table I) for age, use of oral contraceptives, duration of symptoms before treatment, and the index of their severity. A higher proportion of patients treated with butoconazole, however, had had previous episodes of candidiasis $\left(\chi^{2}=1 \cdot 27\right.$, not significant).

TABLE I Characteristics of 68 patients with candidiasis

\begin{tabular}{lll}
\hline & $\begin{array}{l}\text { Patients receiving } \\
\text { miconazole }(n=35)\end{array}$ & $\begin{array}{l}\text { Patients receiving } \\
\text { butoconazole }(n=33)\end{array}$ \\
\hline $\begin{array}{l}\text { Mean age (years) } \\
\text { No (\%) using oral } \\
\text { contraceptives }\end{array}$ & $29 \cdot 9$ & $29 \cdot 1$ \\
$\begin{array}{c}\text { Mean duration of } \\
\text { attack before } \\
\text { treatment (days) }\end{array}$ & $14 \cdot 5$ & $16(48 \cdot 5)$ \\
$\begin{array}{c}\text { No (\%) with } \\
\text { history of } \\
\text { candidiasis }\end{array}$ & $21(60)$ & $12 \cdot 1$ \\
$\begin{array}{c}\text { Mean index } \\
\text { severity of } \\
\text { symptoms }\end{array}$ & $4 \cdot 8$ & $26(78 \cdot 8)$ \\
\hline
\end{tabular}

*Sum of grades of discharge, itching, and burning on four point scale $(0=$ none, $1=$ mild, $2=$ moderate, $3=$ severe $)$.

\section{Results}

Sixty one patients attended for the first follow up visit after a mean of $17 \cdot 1$ (range 7-28) days, and 51 attended for a second follow up visit after a mean of 40.4 (range 22-105) days. Those with positive cultures at the first follow up were not asked to return for the second.
Two patients, both receiving butoconazole, lost their diary cards. Five patients, three receiving butoconazole and two miconazole, failed to use the products exactly as instructed. All were cured and are included in the analysis of results.

The mean number of days to the resolution of itching (table II) was 4.7 in the patients receiving miconazole and 4.8 in those receiving butoconazole. The mean number of days to the resolution of burning was $3 \cdot 7$ in both groups. The patients' assessment of the resolution of discharge was difficult to evaluate: many patients considered that they always had a discharge, others found discharge difficult to distinguish from leakage of cream.

TABLE II Resolution of symptoms in 61 patients with candidiasis

\begin{tabular}{lll}
\hline & \multicolumn{2}{l}{$\begin{array}{l}\text { Mean No of days to resolution in patients } \\
\text { receiving: }\end{array}$} \\
\cline { 2 - 3 } Symptoms & Miconazole & Butoconazole \\
\hline Itching & $4 \cdot 7(\mathrm{n}=30)$ & $4 \cdot 8(\mathrm{n}=25)$ \\
Burning & $3 \cdot 7(\mathrm{n}=25)$ & $3 \cdot 7(\mathrm{n}=20)$ \\
\hline
\end{tabular}

The microbiological cure rates for both products did not differ appreciably at either follow up visit, and over $75 \%$ of patients were free from infection at the second visit (table III).

No serious side effects were experienced, (table IV) but both creams led some patients to complain of stinging on application, and one patient found this severe enough to withdraw from the trial. Six patients receiving butoconazole compared with three receiving miconazole complained of odour, but this difference was not significant. The complaint of odour was not associated with anaerobic vaginosis in either group. More patients receiving miconazole complained of the preparation leaking $\left(\chi^{2}=6 \cdot 44\right.$; $0.025>p>0.01$ ).

\section{Discussion}

The symptomatic and mycological cure rates achieved with the two preparations did not differ

TABLE III Microbiological cure rate in 63 patients with candidiasis

\begin{tabular}{|c|c|c|c|c|c|}
\hline Treatment & $\begin{array}{l}\text { Follow up } \\
\text { visit }\end{array}$ & $\begin{array}{l}\text { Mean (range) } \\
\text { davs after } \\
\text { start } \\
\text { of treatment }\end{array}$ & $\begin{array}{l}\text { No of } \\
\text { patients } \\
\text { attending }\end{array}$ & $\begin{array}{l}\text { Positive } \\
\text { cultures }\end{array}$ & $\begin{array}{l}\text { Cumulative No (\%) } \\
\text { cured }\end{array}$ \\
\hline Miconazole $(n=33)$ & $\begin{array}{l}1 \\
2\end{array}$ & $\begin{array}{l}15 \cdot 9(11-28) \\
40 \cdot 9(25-105)\end{array}$ & $\begin{array}{l}32 \\
27\end{array}$ & $\begin{array}{l}5 \\
3\end{array}$ & $\begin{array}{l}27(84 \cdot 4) \\
25 *(75 \cdot 8)\end{array}$ \\
\hline Butoconazole $(n=30)$ & $\begin{array}{l}1 \\
2\end{array}$ & $\begin{array}{l}18 \cdot 4(7-27) \\
40 \cdot 0(22-99)\end{array}$ & $\begin{array}{l}29 \\
24\end{array}$ & $\begin{array}{l}5 \\
2\end{array}$ & $\begin{array}{l}24(82 \cdot 8) \\
23 *(76 \cdot 7)\end{array}$ \\
\hline
\end{tabular}

*Including one patient whose only follow up was later than 28 days after start of treatment. 
TABLE IV Incidence of side effects of miconazole and butoconazole in 62 patients with candidiasis

\begin{tabular}{lll}
\hline & \multicolumn{2}{c}{ No $(\%)$ reporting side effects receiving: } \\
\cline { 2 - 3 } Side effect & Miconazole $(n=33)$ & Butoconazole $(n=29)$ \\
\hline Leakage & $22(66 \cdot 7)$ & $9(31)$ \\
Staining & $6(18 \cdot 2)$ & $8(27 \cdot 6)$ \\
Odour & $3(9 \cdot 1)$ & $6(20 \cdot 7)$ \\
Stinging & $6(18 \cdot 2)$ & $6(20 \cdot 7)$ \\
\hline
\end{tabular}

appreciably and our results are comparable with those achieved using other imidazole derivatives. ${ }^{67}$

The treatment groups were well matched except for history of candidiasis, which was more common in those receiving butoconazole. If the activity of both drugs were equivalent, increased relapses might have been expected, giving a lower cure rate for butoconazole; but this was not seen. Nine patients (five receiving butoconazole and four miconazole) received antibiotic treatment during follow-up, and one of them (receiving miconazole) subsequently relapsed.

The incidence of side effects with both drugs was relatively high, which may have been a result of the direct and specific questions answered at the time of application. As miconazole was prescribed in a larger volume and for a longer period, it is not surprising that more patients receiving this preparation complained of leakage. Stinging or irritation has been reported with other imidazole drugs, but our complaint rate was higher than usually seen.
The advantage of cream preparations, such as miconazole or butoconazole, is that they can be used to treat both vulval and vaginal candidiasis. This, coupled with the low dose and short treatment period necessary for cure with butoconazole, makes this drug ideal for patients who comply poorly with treatment.

We thank Drs Williams and Newby of Eaton Socon Health Centre for permission to study patients under their care; the Department of Microbiology, St Thomas's Hospital, for mycological studies; and Syntex Pharmaceuticals for provision of the antifungal agents.

\section{References}

1. Beggs WH. The effect of antifungal imidazoles on resting cells of Candida parapsilosis. International Research Communications System Journal of Medical Sciences 1983;11:677.

2. Jacobson JB, Hajman AJ, Gandrup PB, Wiese J, Forsstrom S. First clinical experience with a new vaginal antifungal agent, butoconazole nitrate: a double-blind comparison to miconazole nitrate. Xth World Congress of Gynecology and Obstetrics, October 17-22 1982. San Francisco, USA. New York: Academy Professional Information Services, 1982:368.

3. Walker KAM, Braemer AC, Hitt S, Jones RE, Matthews TR. 1-[4-(4-Chlorophenyl)-2-(2,6-dichlorophenylthio)-n-butyl]-1. $\mathrm{H}$-imidazole nitrate, a new potent antifungal agent. $J$ Med Chem 1978;21:840-3.

4. Hull FM. The management of vaginal discharge. Prescriber's Journal 1982; 22:91-6.

5. Oriel JD. Non-specific urethritis and vaginal discharge. Prescriber's Journal 1976; 16:108-16.

6. Eliot BW, Howat RCL, Mack AE. A comparison between the effects of nystatin, clotrimazole and miconazole on vaginal candidiasis. Br J Obstet Gynaecol 1979; 86:572-7.

7. Gabriel G, Thin RNT. Clotrimazole and econazole in the treatment of vaginal candidosis. British Journal of Venereal Diseases 1983;59:56-8. 